\title{
ESTUDO DA DUCTILIDADE A QUENTE DE VERGALHÕES LAMINADOS SEM USO DA ETAPA DE REAQUECIMENTO*
}

\author{
Francisco Alberto Marreiros da Rocha Filho ${ }^{1}$ \\ Rodrigo Alves Ramos ${ }^{2}$ \\ Antônio Aldenor Pinheiro Neto ${ }^{3}$ \\ Matheus de Lima Vieira ${ }^{4}$ \\ Marcelo José Gomes da Silva ${ }^{5}$
}

\section{Resumo}

No processo de laminação a quente ocorre ocasionalmente a perda de ductilidade a quente que pode causar o fenômeno denominado como "abertura de cabeça" da barra durante a sequência de passes. Essa perda de ductilidade a quente pode ser severa e causar interrupções no processo produtivo. Esse fenômeno pode estar associado a diversos fatores entre eles: composição química do aço; defeitos presentes no tarugo; condições do processo de laminação; e temperatura do aço durante o processo, principalmente nos passes de desbaste e intermediários de laminação. No processo em estudo, a perda de ductilidade a quente ocorre associada à laminação de vergalhões a partir de tarugos oriundos diretamente do lingotamento contínuo. O presente trabalho tem como objetivo avaliar a influência da temperatura e da microestrutura formada ao longo do processo na perda de ductilidade a quente das barras através de um exame comparativo entre os vergalhões laminados com e sem o uso da etapa de reaquecimento.

Palavras-chave: Laminação a quente; Perda de ductilidade a quente; Temperatura; Caracterização Microestrutural.

\section{STUDY OF HOT DUCTILITY OF ROLLED REBARS WITHOUT REHEATING STEP}

\begin{abstract}
In the hot rolling process occasionally occurs the hot shortness which can cause the phenomenon referred to as split ends of bar during the sequence of rolling pass. This hot shortness can be severe and cause disruptions in the production process. This phenomenon may be associated with several factors, such as: chemical composition of steel; defects present on billet; conditions of rolling process; and steel temperature during the process, especially at the roughing and intermediate passes of rolling. In the process under study, hot shortness occurs associated with the rolling of rebars from billets coming directly from continuous casting. The present work has as objective to evaluate the influence of the temperature and the microstructure formed along of process in hot shortness of bars through comparative examination between the rolled rebars with and without the use of reheating step.
\end{abstract}

Keywords: Hot Rolling; Hot shortness; Temperature; Microstructural Characterization.

1 Bacharel em Metalurgia, Mestrando em Ciência dos Materiais, Universidade Federal do Ceará, Assistente Técnico, Aciaria, Gerdau Aços Brasil

2 Bacharel em Metalurgia, Mestrando em Ciência dos Materiais, Universidade Federal do Ceará, Assessor Técnico, Aciaria, Gerdau Aços Brasil

3 Graduando em Engenharia Metalúrgica, Assistente Técnico, Laminação, Gerdau Aços Brasil

4 Graduando em Engenharia Metalúrgica, Universidade Federal do Ceará

5 Doutor em Engenharia Nuclear, Professor Adjunto, Departamento de Engenharia Metalúrgica e de Materiais, Universidade Federal do Ceará 


\section{INTRODUÇÃO}

Os aços laminados constituem uma importante forma final e atendem a diversas aplicações. A laminação de longos é focada na produção de barras e perfis para uso industrial, e de vergalhões para uso na construção civil [1-2].

Em um mercado cada vez mais competitivo, a qualidade dos processos e dos produtos é um grande diferencial para a atração e retenção de clientes e consequente geração de lucros. Ocorrências relacionadas a retrabalhos e sucateamentos de peças durante os processos de fabricação geram perdas e custos indesejáveis. O objetivo é produzir com qualidade sem paradas de produção ou retrabalhos, mas os processos de fabricação e conformação dos aços são dinâmicos e possuem diversas variáveis que precisam ser devidamente controladas de forma a reduzir ou eliminar potenciais falhas.

Relacionada à competitividade e a redução de custos no processo, uma nova alternativa surge na produção de laminados de aço: Trata-se da laminação direta, processo no qual os tarugos de aço são laminados diretamente a partir do lingotamento contínuo, sem que haja a necessidade do uso da etapa de reaquecimento prévia a laminação. A Figura 1 mostra uma representação esquemática do processo de laminação a quente de vergalhões para construção civil, mostrando a diferença entre as rotas de produção com e sem o uso da etapa de reaquecimento prévia a laminação.

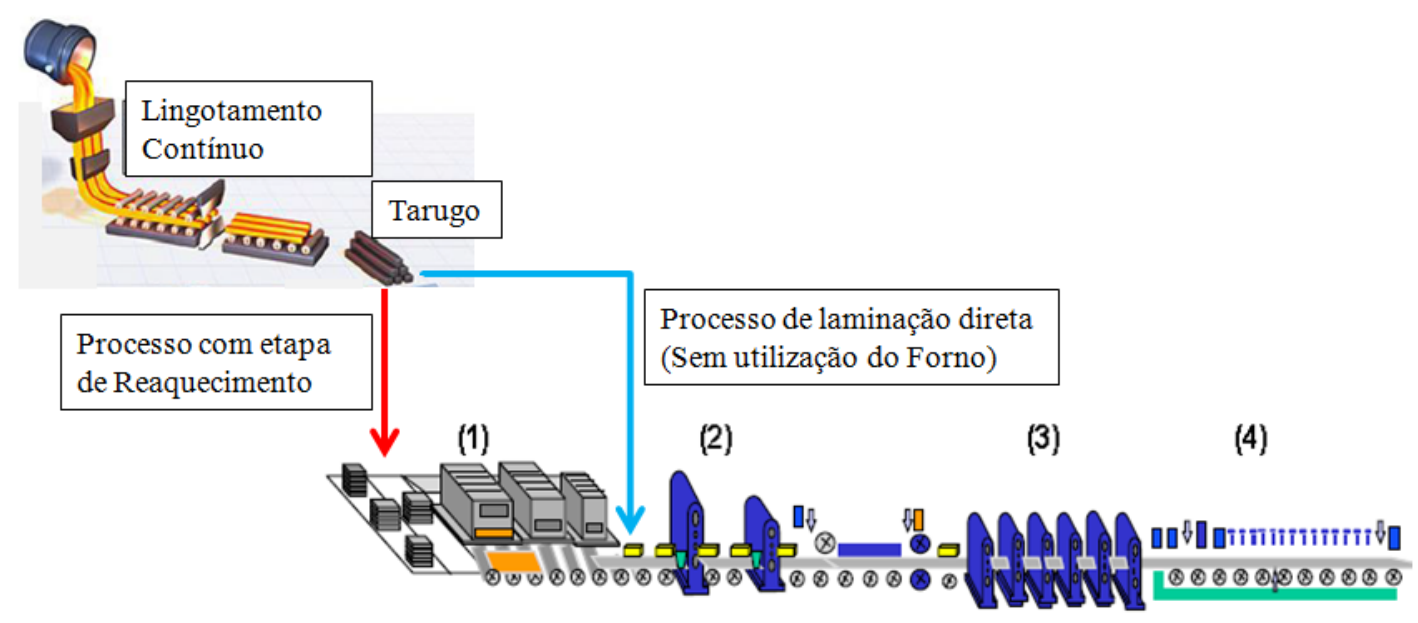

(1) Forno de reaquecimento / (2) Laminador (desbaste)

(3) Laminador (acabamento)/ (4) Leito de resfriamento

Figura 1 - Diagrama esquemático representando as rotas do processo de laminação. Fonte: Adaptado de SOUZA [3].

A ocorrência de defeitos no processo de laminação é um importante problema para a indústria, afetando a produção em larga escala de produtos longos, por exemplo. A prevenção desses defeitos em particular exerce um papel importante para a melhoria da qualidade e aumento de produtividade. Durante a laminação, o aço pode sofrer perda de ductilidade, relacionada a diversos fatores tais como: composição química do aço, qualidade do tarugo (relacionada aos parâmetros do lingotamento que podem gerar defeitos), controle de temperatura prévia aos primeiros passes de laminação e condições do processo de laminação [4-5].

Durante a laminação, a perda de ductilidade a quente gera um fenômeno denominado como "abertura de cabeça", que geralmente inicia-se com a formação 
de uma trinca, e dependendo da severidade desta, poderá ocorrer a separação da barra em duas partes ao longo de seu eixo central. Esse fenômeno gera perdas de barras, sendo responsável também por paradas, riscos operacionais e de segurança e danos aos equipamentos do laminador. Essa "abertura de cabeça" pode estar associada ao processo de laminação de tarugos oriundos diretamente do lingotamento contínuo sem a utilização de fornos de reaquecimento. A Figura 2 mostra as barras que sofreram perda de ductilidade a quente e a separação na direção de laminação, ao longo do eixo central da barra.

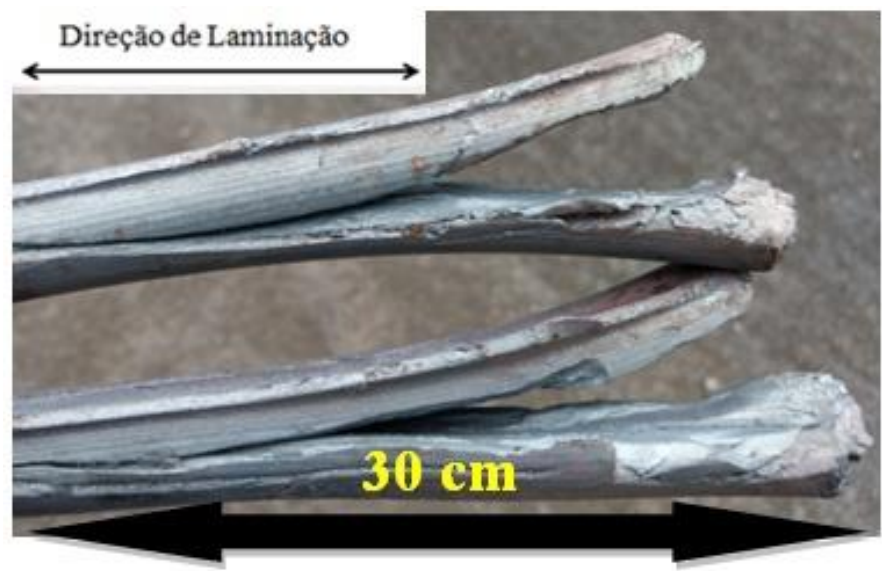

Figura 2 - Barra laminadas apresentando "abertura de cabeça". Fonte: Própria do autor.

\subsection{Composição Química}

A perda de ductilidade a quente do aço e a susceptibilidade a trincas durante o lingotamento contínuo tem sido associada à presença de oxisulfetos e sulfetos de ferro líquidos nos contornos de grão. A composição química do aço é um dos fatores frequentemente relacionados à ductilidade a quente e a relação $\mathrm{Mn} / \mathrm{S}$ é amplamente utilizada como indicativo desta propriedade. $O$ enxofre é dissolvido no aço líquido e o sulfeto de manganês não precipita antes da solidificação, pois a solubilidade do MnS no aço líquido é grande. Então quanto maior o teor de $\mathrm{Mn}$, maior tendência a formação de $\mathrm{MnS}$, do contrário oxisulfetos e sulfetos de ferro poderão ser formados e isso deve ser evitado.O ponto de fusão das inclusões de (Fe, Mn)S é $1190^{\circ} \mathrm{C}$ e o ponto de fusão do composto eutético Fe-FeS-FeO é de $980^{\circ} \mathrm{C}$. Durante a laminação a quente estes sulfetos estão presentes como fase líquida causando a formação de trincas e consequente perda de ductilidade do aço $[4 ; 6-7]$.

Toledo (1993) propõe uma relação Mn/S crítica, dada pela equação:

$$
(\mathrm{Mn} / \mathrm{S}) \mathrm{c}=1,345^{*}[\%]^{-0,7934}
$$

Onde S é o teor de enxofre.

Taylor et al. [8] mostraram que as análises por microscopia eletrônica da área onde a trinca ocorreu possuía uma camada rica em enxofre e ausência de quantidades significantes de manganês, indicando a presença de sulfetos de ferro com baixo ponto de fusão, causando a perda de ductilidade a quente. 


\subsection{Temperatura de Laminação}

Durante a laminação a quente, o aço a altas temperaturas com grãos grosseiros é deformado pelos cilindros de laminação, formando grãos alongados. Ao deixar os cilindros, os grãos se recristalizam num processo conhecido como recristalização estática, onde este é influenciado pelas taxas de deformação, temperatura e tamanho de grão inicial. A taxa de recristalização estática cresce proporcional ao aumento da deformação. A recristalização pode ocorrer durante a deformação se houver energia suficiente acumulada prévia ao passe de laminação, e essa é denominada de recristalização dinâmica [9-10].

Uma das principais formas de elevar a temperatura do material no processo de laminação a quente é através do uso de fornos de reaquecimento. Estes constituem uma etapa intermediária entre os processos de lingotamento contínuo e laminação a quente. $O$ processo de reaquecimento tem grande efeito no tamanho de grão da austenita e na uniformidade deste ao longo da seção do produto semi-acabado [11-12].

A Figura 3 mostra os resultados obtidos experimentalmente de crescimento de grão isotérmico quando a taxa de aquecimento é de $5^{\circ} \mathrm{C} / \mathrm{s}$.

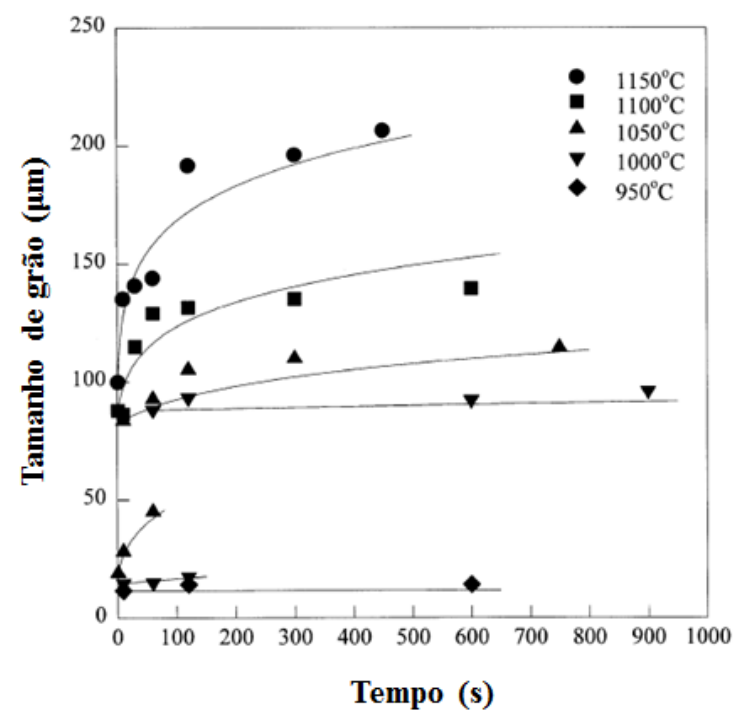

Figura 3 - Crescimento de grão da austenita em um aço $\mathrm{A} 36$ com $0,17 \% \mathrm{C}$ com taxa de aquecimento de $5^{\circ} \mathrm{C} / \mathrm{s}$ a partir da temperatura ambiente. Fonte: Adaptado de MILITZER et al. [13].

Uma nova alternativa na produção de aços longos é a laminação a quente a partir do semi-acabado vindo diretamente do processo de lingotamento contínuo, sem a necessidade de sofrer um processo de reaquecimento. A grande vantagem dessa prática é a economia de energia no processo proporcionada pela redução do consumo de combustíveis nos fornos.

\section{MATERIAIS E MÉTODOS}

O aço utilizado neste estudo para a fabricação dos vergalhões é classificado como aço baixo carbono, com composição química similar ao aço SAE 1020. 


\subsection{Medição de Temperatura}

A coleta de temperaturas foi realizada de duas formas distintas:

1) Levantamento do perfil de perda de temperatura do tarugo desde o lingotamento contínuo até o início do primeiro passe de laminação. Essas temperaturas foram coletadas com o uso de termômetros infravermelhos fixos (denominados como pirômetros) em três pontos ao longo do caminho entre lingotamento contínuo e laminação.

2) Uso de câmera de imagem térmica da marca $\mathrm{Flir}^{\circledR}$ modelo T420 para coleta de imagens de perfil térmico (termografias) dos tarugos ao longo do seu comprimento. Essas termografias foram coletadas em um rejeitador de tarugos localizado imediatamente antes do primeiro passe de laminação (desbaste). Foram registradas termografias de tarugos laminados com e sem o uso da etapa de reaquecimento.

\subsection{Caracterização Microestrutural}

Foram coletadas amostras de tarugos para fins de comparação, mostrando a influência de cada processo na microestrutura obtida e consequentemente na perda de ductilidade a quente, responsável pela "abertura de cabeça" das barras, geralmente nos passes médios de laminação.

As amostras coletadas foram cortadas, preparadas metalograficamente e atacadas em solução de nital $2 \%$ para que fosse revelada a microestrutura. Foram realizadas micrografias e medições dos tamanhos médios de grão utilizando 0 software AxioVs40x64 V 4.9.1.0 presente no microscópio ótico da marca Zeiss ${ }^{\circledR}$, modelo AxioCam ICc 5 seguindo a norma ASTM E 112 utilizando o método do intercepto linear.

A avaliação microestrutural quanto à presença de sulfetos foi realizada através da técnica de Espectroscopia de raios-X por dispersão em energia (Energydispersive $X$-ray spectroscopy - EDS), o equipamento utilizado para essa análise foi - Microscópio Eletrônico de Varredura da marca Tescan ${ }^{\circledR}$, modelo VEGA3-XM com aceleração de tensão de $20 \mathrm{KV}$, no modo EDS. Nesse caso uma amostra da região onde houve a "abertura de cabeça" foi coletada e analisada via técnica EDS com o objetivo de verificar a presença de sulfeto de ferro ao longo da microestrutura.

\subsection{Ensaio de Dureza}

Associada a análise de temperaturas e microestruturas, foram realizados ensaios de dureza, simulando as condições prévias a laminação para ambas as rotas de produção, associando os valores obtidos nos ensaios com os parâmetros de temperatura e microestrutura, avaliando como estes influenciam na perda de ductilidade a quente do aço. Foram simuladas duas condições a fim de avaliar como o tempo e a temperatura de exposição no forno influenciam nas propriedades mecânicas do aço antes deste ser laminado. Para realização dessas simulações, foram retiradas amostras de tarugo em triplicata. A primeira condição simulou o processo com uso do forno de reaquecimento, onde as amostras de tarugos foram colocadas no interior de um forno do tipo mufla permanecendo $1 \mathrm{~h}$ a $550^{\circ} \mathrm{C}$ (préaquecimento), $1 \mathrm{~h}$ a $1060^{\circ} \mathrm{C}$ (aquecimento) e 30 minutos a $1200^{\circ} \mathrm{C}$ (encharque), e por fim estas foram resfriadas ao ar. A segunda condição simulou o tarugo laminado diretamente, ou seja, a amostra foi retirada do tarugo, resfriada ao ar e não passou por nenhum tratamento térmico. 
Os ensaios de dureza foram realizados no durômetro de escala Brinell utilizando penetrador esférico de aço com $2,5 \mathrm{~mm}$ de diâmetro e com aplicação de 187,5 Kgf de carga, seguindo a norma ASTM E10.

\section{RESULTADOS E DISCUSSÃO}

Para apresentação dos resultados, serão utilizadas as seguintes siglas para cada processo: FR - para o processo de laminação com a utilização de forno de reaquecimento; LD - para o processo de laminação de tarugos oriundos diretamente do lingotamento contínuo.

\subsection{Análise de Temperaturas}

Para fins de comparação entre os processos FR e LD, foram avaliados os perfis de perda de temperatura ao longo de ambos os processos. Os gráficos foram construídos utilizando a média dos valores coletados. A Figura 4 mostra os referidos perfis.

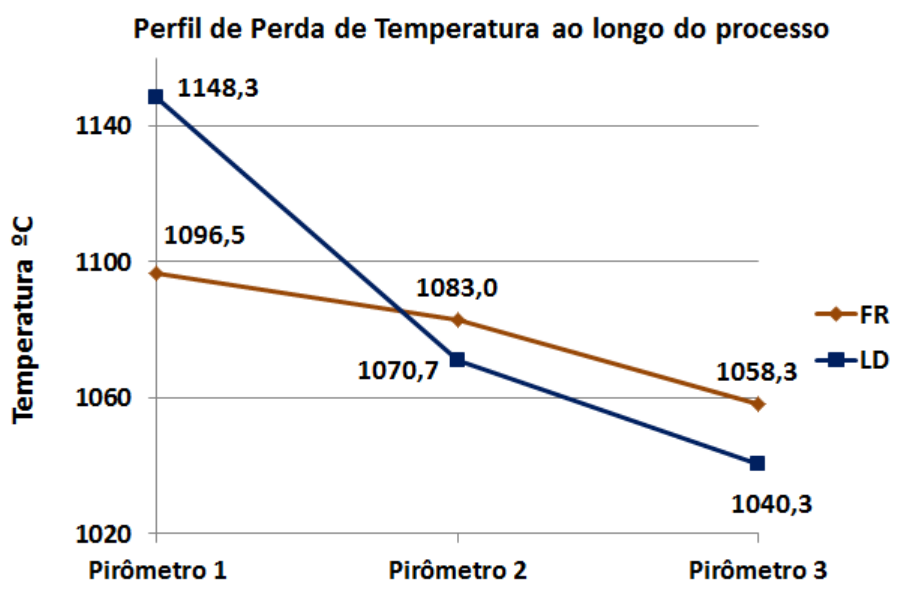

Figura 4 - Perfis de perda de temperatura ao longo de ambos os processos. Fonte: Própria do autor.

A partir dos perfis apresentados, podemos observar que a temperatura registrada no primeiro pirômetro no processo LD (saída do lingotamento contínuo) é superior a do processo FR (saída do forno de reaquecimento). Houve uma maior queda de temperatura entre os pirômetros 1 e 2 para o processo LD. A mesma tendência continua entre os pirômetros 2 e 3 . O pirômetro 3 encontra-se imediatamente antes do primeiro passe de laminação. Observou-se que no processo LD a temperatura na entrada dos passes de desbaste é menor comparada ao processo FR. Esse fator contribui para a perda de ductilidade a quente durante a laminação.

Uma segunda análise comparativa de temperaturas entre os processos foi realizada a partir da coleta de termografias que mostram os perfis de temperatura de diversas regiões ao longo do tarugo. As Figuras 5 e 6 mostram as termografias coletadas para tarugos de ambos os processos. 
CAUDA

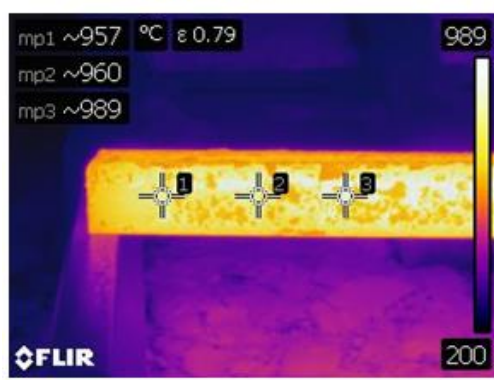

CENTRO

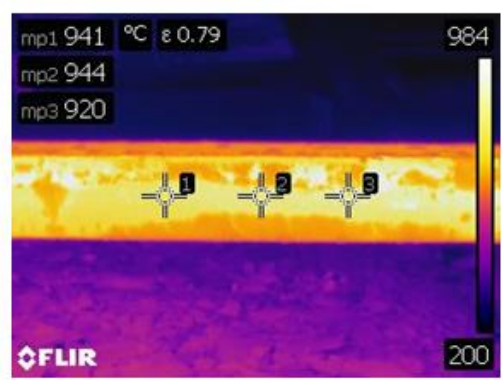

CABEÇA

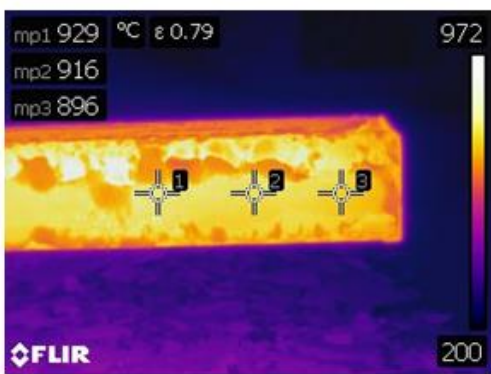

Figura 5 - Termografias com perfil de temperatura nas faces e ao longo do comprimento do tarugo para o processo LD. Fonte: Própria do autor.

CAUDA

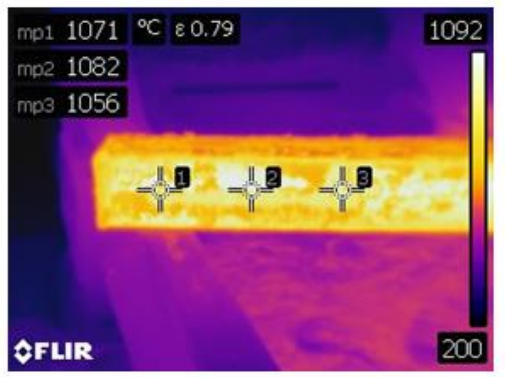

CENTRO

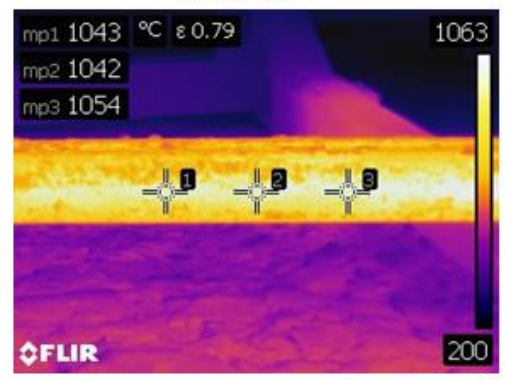

CABEÇA

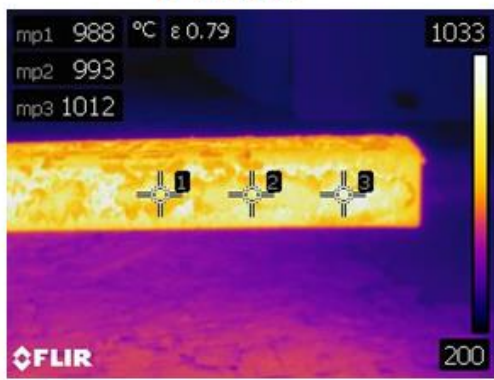

Figura 6 - Termografias com perfil de temperatura nas faces e ao longo do comprimento do tarugo para o processo FR. Fonte: Própria do autor.

A partir das termografias apresentadas para ambos os processos confirmou-se a tendência que as barras do processo LD possuem em perder maior quantidade de temperatura comparada ao processo FR. A temperatura na cabeça do tarugo é um dos pontos de maior criticidade, visto que essa região apresenta menores temperaturas, é a primeira a entrar em contato com os cilindros durante os passes de laminação e nessa mesma região do tarugo ocorre o início da "abertura" ao longo do eixo central da barra causada pela perda de ductilidade a quente. A perda de temperatura no tarugo gera um impacto negativo na ductilidade a quente do material.

A Figura 7 exibe o perfil de temperatura com os valores médios coletados nas termografias ao longo do comprimento do tarugo.

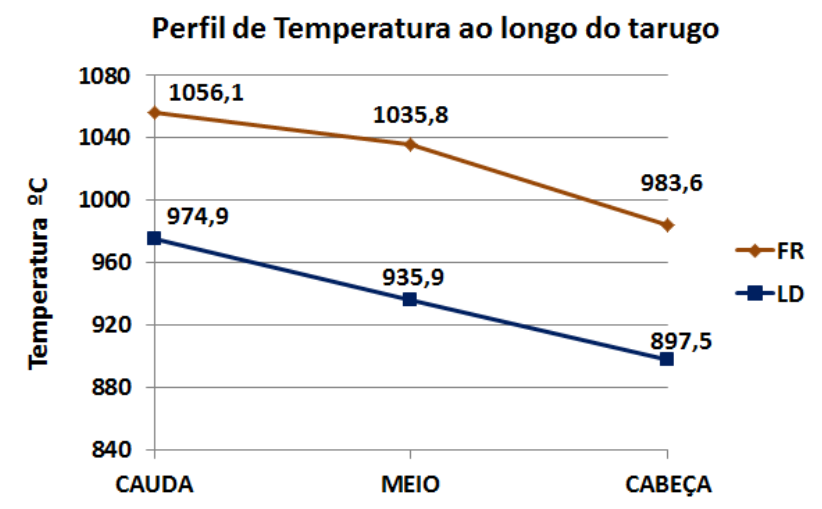

Figura 7 - Perfil de temperatura baseado nas análises termográficas. Fonte: Própria do autor. 


\subsection{Análise Microestrutural}

Relacionado à perda de ductilidade a quente, os principais aspectos microestruturais observados foram o tamanho de grão e a presença de sulfetos (principalmente FeS) nas amostras. A Figura 8 apresenta o comparativo entre 0 tamanho de grão dos tarugos utilizados em ambos os processos.

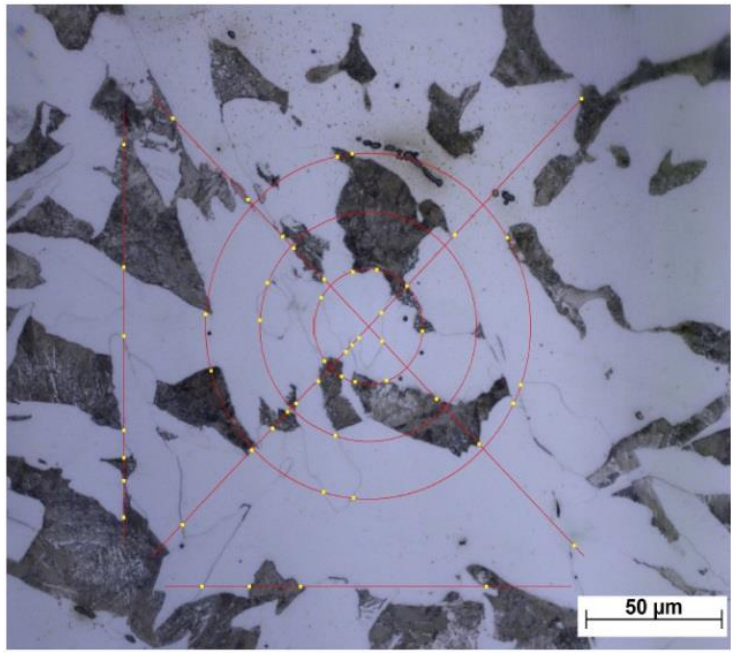

(a)

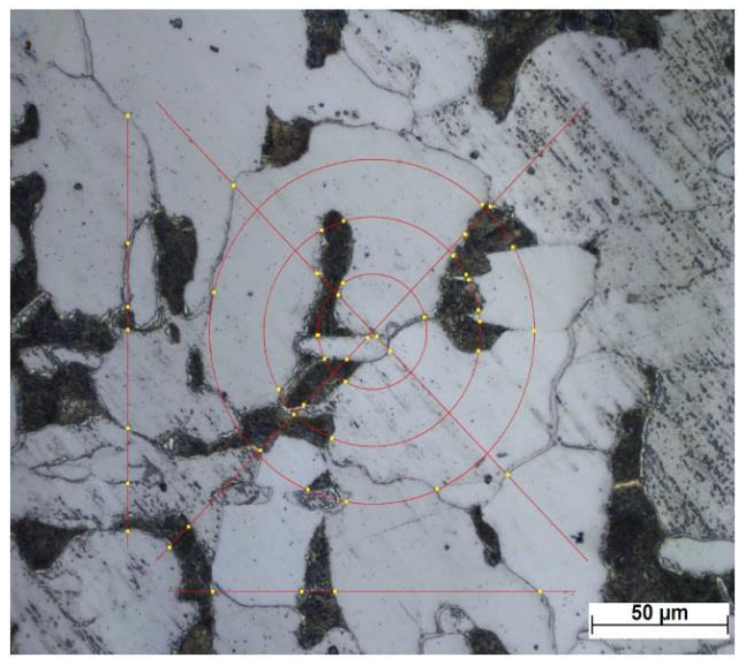

(b)

Figura 8 - Micrografias óticas prévias a laminação (Tarugos): (a): Processo FR. Tamanho de grão ASTM G $6\left(\mathrm{~d}_{\text {médio }}=44,9 \mu \mathrm{m}\right) ;(\mathrm{b})$ : Processo LD. Tamanho de grão ASTM G $7\left(\mathrm{~d}_{\text {médio }}=31,8 \mu \mathrm{m}\right)$. Aumento 500x. Fonte: Própria do autor.

Como esperado, observou-se que o tarugo que passou pelo processo de reaquecimento (Processo FR) antes de ser laminado apresentou grãos maiores, isso é atribuído ao tempo de residência considerável a elevadas temperaturas, variando de $1080^{\circ} \mathrm{C}$ a $1200^{\circ} \mathrm{C}$ entre as zonas de aquecimento e de encharque do forno. A ocorrência de grãos maiores proporcionou uma menor área de contorno de grão, o que favorece uma maior ductilidade a quente do aço durante o processo de laminação. $\mathrm{O}$ tarugo do processo LD apresentou uma estrutura bruta de fusão com grãos mais alongados e refinados, proporcionando um aumento na área dos contornos de grão, sendo responsável pela redução na ductilidade a quente do material.

Adicional ao tamanho de grão, outro fator que contribui para a perda de ductilidade a quente no processo de laminação de tarugos diretamente do lingotamento (LD) é a presença de sulfeto de ferro (FeS).

A Figura 9 mostra a análise por Espectroscopia de raios-X por dispersão em energia (EDS) realizada em uma barra que apresentou "abertura de cabeça". A região analisada pertencia à seção onde houve a separação. Foi realizada a comparação entre os elementos presentes em um ponto no interior do sulfeto com outro ponto na matriz do aço. 


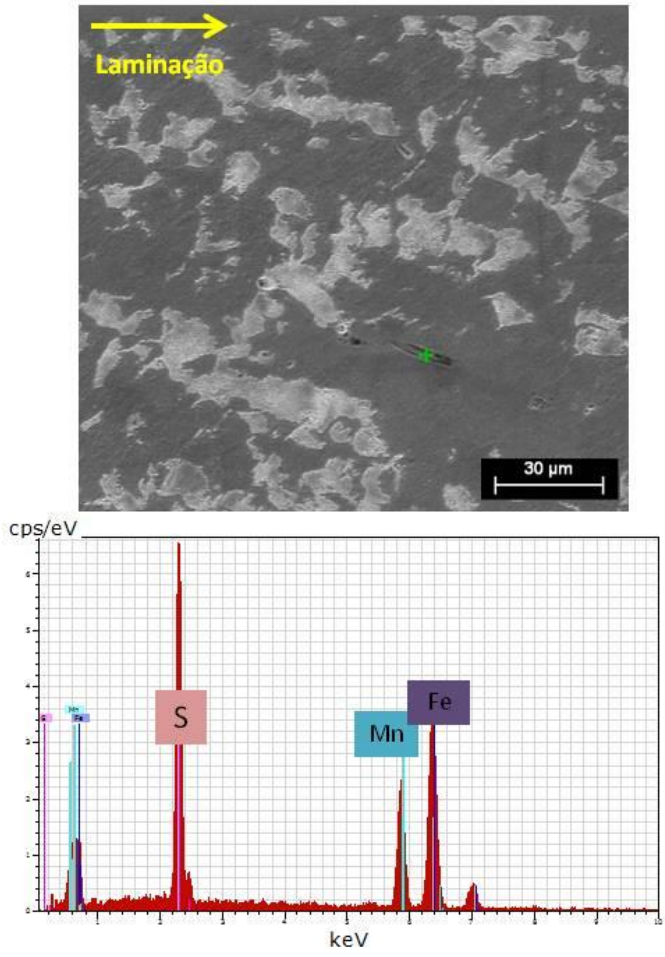

(a)
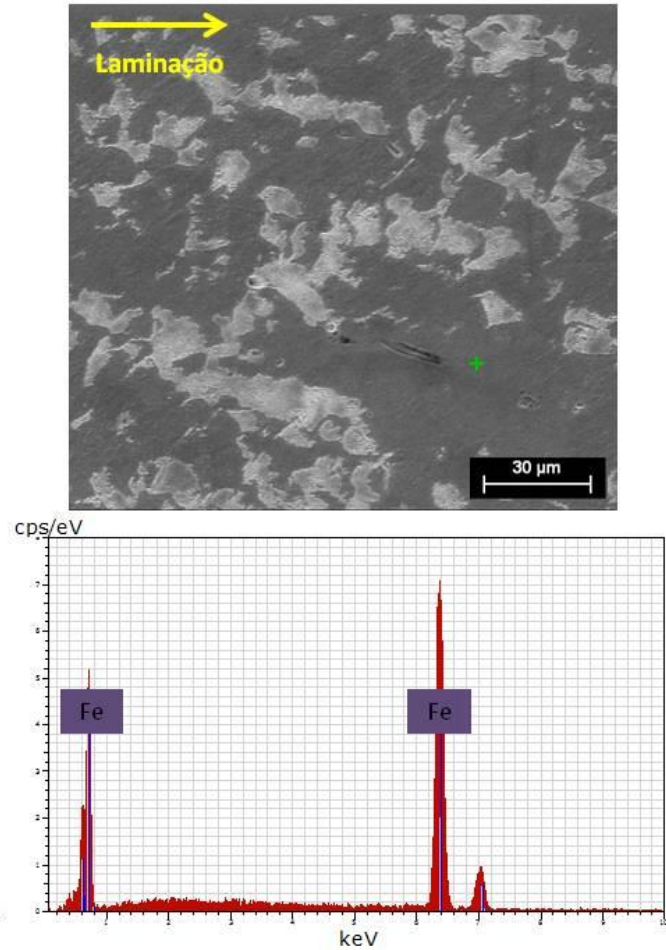

(b)

Figura 9 - Análises por EDS na amostra da barra com "cabeça aberta" (a): Ponto no interior do sulfeto formado; (b): Ponto sobre a matriz do aço. Aumento 1000x. Fonte: Própria do autor.

No espectro correspondente ao ponto interno ao sulfeto, observou-se a presença de $\mathrm{S}$, Mn e $\mathrm{Fe}$, indicando que além da formação de $\mathrm{MnS}$, houve a formação de FeS que é um dos fatores responsáveis pela perda de ductilidade a quente das barras.

\subsection{Medidas de Dureza}

Os resultados dos ensaios de dureza realizados nas amostras onde foram simuladas as condições para ambos os processos forneceram um indicativo da ductilidade do aço para ambos os processos. A Figura 10 apresenta o perfil de dureza para ambas as condições.

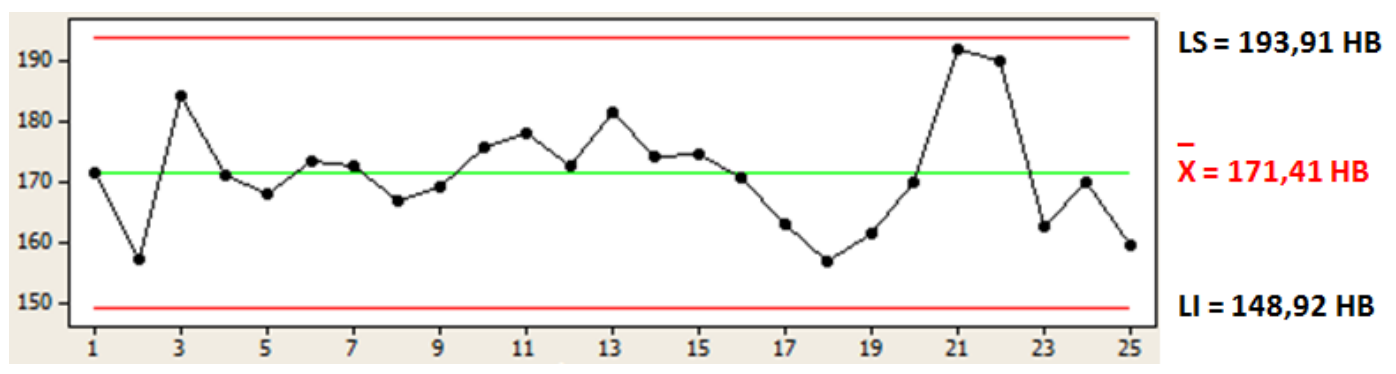

(a) 


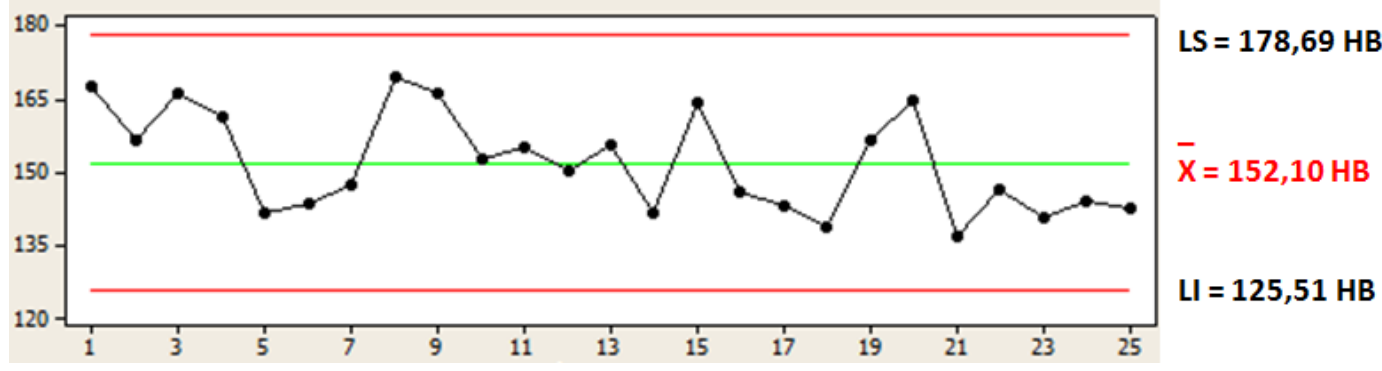

(b)

Figura 10 - Perfil de dureza Brinell (a): Condição LD; (b): Condição FR. Fonte: Própria do autor.

Foi comprovado que na condição onde foi simulado o processo $F R$, o maior tamanho de grão prévio a laminação proporcionou valores de dureza Brinell inferiores comparados ao processo LD. No processo FR, o tempo e a temperatura no interior do forno favorecem o crescimento de grãos, proporcionando uma maior ductilidade do aço durante o processo de laminação a quente.

\subsection{Ocorrências de "Abertura de Cabeça"}

Foram levantadas as ocorrências de "abertura de cabeça" no período de 1 ano na Usina Gerdau Cearense. A Figura 11 mostra o gráfico com as frequências por bitolas.

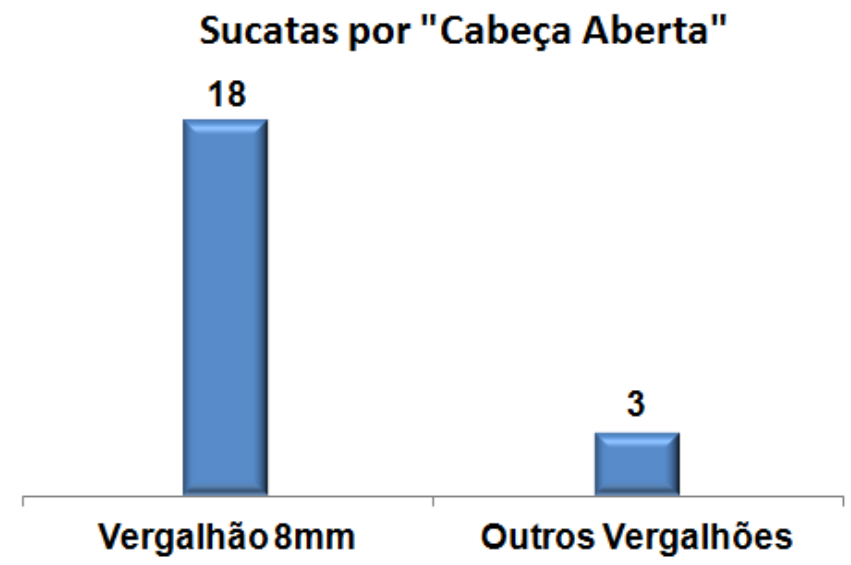

Figura 11 - Ocorrências de "abertura de cabeça" por produto. Fonte: Própria do autor.

Sabendo que a configuração dos passes do trem de desbaste é a mesma para todas as bitolas, observou-se que o produto com maior incidência de "abertura de cabeça" foi o vergalhão $8 \mathrm{~mm}$, visto que esse apresenta maiores reduções entre os passes médios de laminação, gerando maiores esforços trativos perpendiculares a direção de laminação. Fato esse comprovado pela Equação 2 de Misaka e Yoshimoto apud Byon, $\mathrm{Na}$ e Lee [14] e Nalawade et al. [11], que determina a tensão média de escoamento, termo utilizado para descrever a resistência do metal a deformação. No presente trabalho, essa tensão de escoamento é tratada como $\sigma_{\text {def. }}$

$$
\sigma_{\text {def }}=\left\{\exp \left(0,126-1,75[C]+0,594[C]^{2}+\frac{2851+2968[C]-1120[C]^{2}}{T}\right)\right\}(\varepsilon)^{0,21}(\grave{\varepsilon})^{0,13}
$$


Onde: [C] é o teor de carbono; $\varepsilon$ é a deformação; $\dot{\varepsilon}$ é a taxa de deformação e T é a temperatura durante a deformação.

A Tabela 1 mostra os valores calculados para $\sigma_{\text {def }}$ em cada passe médio de laminação a partir da equação 2, utilizando os parâmetros reais do processo.

Tabela 1 - Valores calculados para $\sigma_{\text {def }}$ nos passes médios de laminação. Fonte: Própria do autor.

\begin{tabular}{|c|c|c|c|c|c|}
\hline \multicolumn{6}{|c|}{ PASSES TREM MÉDIO } \\
\hline BITOLA & & M1 & M2 & M3 & M4 \\
\hline $8 \mathrm{~mm}$ & \multirow{4}{*}{$\sigma_{\text {def }}(\mathrm{MPa})$} & 150,3 & 146,4 & 163,8 & 167,1 \\
\hline $10 \mathrm{~mm}$ & & 147,9 & 142,2 & 151,9 & 154,6 \\
\hline $12,5 \mathrm{~mm}$ & & 145,3 & 134,9 & Não possui & Não possui \\
\hline $16 \mathrm{~mm}$ & & 147,5 & 143,8 & Não possui & Não possui \\
\hline
\end{tabular}

\section{CONCLUSÃO}

O processo de laminação a quente de vergalhões a partir de tarugos vindos diretamente do lingotamento contínuo mostrou-se como uma excelente alternativa ao processo de laminação a quente tradicional com o uso da etapa de reaquecimento, principalmente no que diz respeito à economia gerada pela redução da utilização, e consequentemente, do consumo de combustíveis nos fornos de reaquecimento. Porém esse processo de laminação direta proporciona ao aço diferentes características comparadas ao processo via forno de reaquecimento, que podem acarretar na perda de ductilidade a quente da barra durante a laminação.

Ao avaliar os fatores que influenciam na perda de ductilidade a quente das barras durante os passes médios de laminação observou-se que:

(1) A perda de temperatura ao longo do processo de laminação e ao longo do comprimento do tarugo é maior no processo de laminação direta;

(2) Os tarugos e as barras laminadas diretamente a partir do lingotamento contínuo apresentaram granulometria refinada comparada ao processo via forno de reaquecimento;

(3) Foi identificado indícios da presença de FeS em barras que apresentaram "abertura de cabeça" nos passes médios de laminação;

(4) As medidas de dureza em tarugos onde foram simuladas as condições prévias a laminação mostraram que os tarugos laminados direto apresentam maiores durezas proporcionadas pela estrutura bruta de fusão com grãos refinados, comparados ao processo via forno com granulometria grosseira;

(5) A resistência média do metal a deformação é maior para bitolas com maiores deformações e taxas de deformações.

O alinhamento desses fatores favorece a perda de ductilidade a quente do aço durante a laminação. Mitigamos a ocorrência da "abertura de cabeça" em bitolas com maiores reduções (Ex: Vergalhão $8 \mathrm{~mm}$ ) no processo de laminação direta, otimizando os fatores de temperatura e composição química (relacionada principalmente a dessulfuração do aço). 


\section{Agradecimentos}

Ao Conselho Nacional de Desenvolvimento Científico e Tecnológico (CNPq - PROJETO 435666/2016-9 - Implantação do Direct Rolling (Laminação Direta) - Processo: 350381/2016-0), ao Instituto Euvaldo Lodi (IEL-CE), e a Gerdau Aços Brasil - Unidade Cearense pelo auxílio financeiro para a realização dessa pesquisa.

Ao Programa de Pós-Graduação em Engenharia e Ciência de Materiais da Universidade Federal do Ceará, em especial ao Laboratório de Caracterização de Materiais - LACAM pelo uso de suas instalações para a realização dos experimentos.

\section{REFERÊNCIAS}

1 RIZZO, E. M. S. Introdução aos processos siderúrgicos. São Paulo: Associação Brasileira de Metalurgia, Materiais e Mineração - ABM, 2005. 150 p.

2 CAMPBELL, F.C. (Ed.). Metals Fabrication - Understanding the Basics. St. Louis, USA: ASM International, 2013. 449 p.

3 SOUZA, A. L. Estudo da Tensão Média de Escoamento de Aços Laminados em Tiras a Quente. Dissertação - Pós-Graduação em Engenharia Metalúrgica e de Minas, Escola de Engenharia, Universidade Federal de Minas Gerais - UFMG, Belo Horizonte, 2010. $53 \mathrm{p}$.

4 MADIAS, J. Split Ends During Long Products Rolling: Billet Quality or Rolling Process? In: Aistech - Proceedings, Buenos Aires. 2014; p. 2591-2602.

5 PANDEY, J. C.; RAJ, M.; CHOUBEY, P. N.. Split Ends and Cracking Problem During Hot Rolling of Continuously Cast Steel Billets. Journal Of Failure Analysis And Prevention. 2008; 9 (1): 88-96,

6 TOLEDO, G. A.; CAMPO, O.; LAINEZ, E. Influence of sulfur and Mn/S ratio on the hot ductility of steels during continuous casting. Steel research. 1993; 64 (6): 292-299.

7 GUBENKO, S. I.; GALKIN, A. M. Nature of the red-shortness of steel. Metal Science and Heat Treatment. 1984; 26 (10): 732-737.

8 TAYLOR, G.; MAYLAND, K.; BAGSHAW, P.A.; INGHAM, P.M. The cause of end splitting during the rolling of free cutting steels, Commission of the European Communities, Report EUR 10156, 1986. 153 p.

9 HOMSHER, C. N. Determination of the Non-Recrystallization Temperature $\left(T_{n r}\right)$ in Multiple Microalloyed Steels. Thesis - Degree of Master of Science (Metallurgical and Materials Engineering), Department of Mining and Metallurgical Engineering, Colorado School of Mines, Golden, 2013. 106 p.

10 BAI, D. Q. Effect of Rolling Parameters on the No-Recrystallization Temperature $\left(T_{n r}\right)$ in $\mathrm{Nb}$-Bearing Steels. Thesis - Degree of Master of Engineering, Department of Mining and Metallurgical Engineering, McGill University, Montreal, 1993. $139 \mathrm{p}$.

11 NALAWADE, R.S. et al. Simulation of hot rolling deformation at intermediate passes and its industrial validity. International Journal Of Mechanical Sciences. 2013; 77: 8-16.

12 JANSTO, S. G. Reheat Furnace Operational Parameters Affecting Hot Roll Quality of Microalloyed Long Products. International Conference on Metallurgy and Materials METAL, Brno, Czech Republic. Tanger Ltd. 2015.

13 MILITZER, M. et al. Austenite Grain Growth Kinetics in Al-Killed Plain Carbon Steels. Metallurgical and Materials Transactions A. 1996; 27 (11): 3399-3409.

14 BYON, S. M.; NA, D. H.; LEE, Y. S. Flow stress equation in range of intermediate strain rates and high temperatures to predict roll force in four-pass continuous rod rolling. Transactions of Nonferrous Metals Society of China. 2013; 23 (3): 742-748. 